\title{
Men in maternity study: Results from the pre-intervention survey of pregnant women and their husbands at the three interventions, and of only women at three control Employees' State Insurance Corporation dispensaries in Delhi, India: Preliminary findings
}

\author{
Anurag Mishra \\ Population Council \\ Leila Caleb-Varkey \\ Emma Ottolenghi \\ Anjana Das \\ Dale Huntington
}

See next page for additional authors

Follow this and additional works at: https://knowledgecommons.popcouncil.org/departments_sbsr-rh

Part of the Demography, Population, and Ecology Commons, Family, Life Course, and Society

Commons, International Public Health Commons, and the Maternal and Child Health Commons

How does access to this work benefit you? Let us know!

\section{Recommended Citation}

Mishra, Anurag, Leila Caleb-Varkey, Emma Ottolenghi, Anjana Das, Dale Huntington, and Susan E. Adamchak. 2002. "Men in maternity study: Results from the pre-intervention survey of pregnant women and their husbands at the three interventions, and of only women at three control Employees' State Insurance Corporation dispensaries in Delhi, India," FRONTIERS report of preliminary findings. New Delhi: Population Council. 


\section{Authors}

Anurag Mishra, Leila Caleb-Varkey, Emma Ottolenghi, Anjana Das, Dale Huntington, and Susan E. Adamchak 


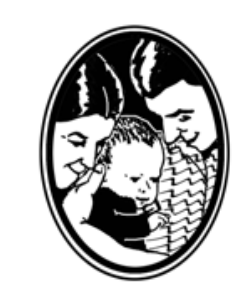

\title{
MEN IN MATERNITY STUDY: Results from the Pre-Intervention Survey of Pregnant Women and their Husbands at the Three Intervention, and of only Women at Three Control Employees' State Insurance Corporation Dispensaries in Delhi, India
}

\author{
Preliminary Findings
}

\author{
Contributors \\ Anurag Mishra, M.P.S., M.Sc. \\ Leila Caleb Varkey, Sc.D. \\ Emma Ottolenghi, M.D. \\ Anjana Das, M.B.B.S., D.C.H. \\ Dale Huntington, Sc.D. \\ Susan Adamchak, Ph.D.
}

New Delhi, India

July 2002 


\section{ACKNOWLEDGEMENT}

We would like to acknowledge the active participation and support from all the staff of six Employees' State Insurance Corporation (ESIC) dispensaries where the baseline surveys were carried out. We express our thanks to the women and men for participating in the study and being interviewed during their antenatal visit to the dispensaries.

We extend our special thanks to Dr. Rakesh Chander (Director), Dr. Surinder Kumar and Dr. S.K.Kukreja from ESIC Directorate (Medical), Delhi for their immense interest and continued support while conducting the surveys. We are grateful to Dr. Sushanta Kumar Banerjee and his team of interviewers and supervisors from TNS MODE for their detailed and thorough efforts during the interview process and survey reporting. We wish to thank our colleagues at Population Council in Delhi and Washington D.C., especially to Sohini Roychowdhury and Geetha Vaithyanathan for editorial assistance. 


\section{EXECUTIVE SUMMARY}

The FRONTIERS in Reproductive Health program of the Population Council is conducting a Operations Research Study, called Men in Maternity (MiM) that investigates the impact of male participation in a new model of maternity care that is gender sensitive and provided at the primary care level on the outcomes related to the reproductive health of men, women and the pregnancy. The immediate objectives are to increase the use of family planning methods in the postpartum period and promote STI preventive practices in men and women. The Study is being conducted in South Africa and India. In India it is being conducted in collaboration with the Employees State Insurance Corporation (ESIC), Delhi Directorate.

This OR Study uses a quasi-experimental study design to examine the effects of the intervention. Along with the collaborating partners, Population Council staff chose six of the 34 ESIC dispensaries in Delhi with the highest antenatal clinic attendance as sites for the study. Three of these were assigned the intervention and three acted as controls. A sample size of 450 pregnant women was estimated for each group, keeping in mind the key variables and the likelihood of a loss of participants during the follow-up six-month postpartum interviewing period. At the end of the Baseline Survey 581 women and 488 of their husband's had been interviewed at the intervention sites and 486 women had been interviewed at the control sites.

The data presented in this report is derived from the Baseline Survey conducted from November 2000 to November 2001, of pregnant women between 10 and 26 weeks of gestation who were attending antenatal clinics at the 6 ESIC dispensaries. Interviews were conducted with consenting subjects and in cases with men, only after the women first agreed to involve their husbands. Both men and women were interviewed in the experimental clinics and only women were interviewed in the control clinics.

The baseline data provides us with the following preliminary conclusions:

\section{Individual's general characteristics:}

- Most women who were informed of this project agreed to participate and, in the case of the experimental clinics, to involve their husband both in the survey and the new maternity service model.

- With minor differences, control and experimental women were quite similar in their socio-demographic characteristics. For the remainder of this discussion, only intervention women's data will be described.

- In general, participating women were 4.5 years younger and far less educated than their husbands and only 8 percent of the women were gainfully employed.

- About four-fifth of the households had either a radio or television, leading to the conclusion that mass media had an extensive outreach among a large majority of the Delhi ESIC's insured person population.

\section{Pregnancy history:}

- This cohort of women was generally of low parity with the mean number of living children being 1.1. Only 8 percent of the women had three or more children. 


\section{Unmet family planning need:}

- The number of MTPs/elective abortions increased with parity, indicating an unmet need for FP in the ESIC population.

- Other strong indicators of unmet need included a birth interval of less than 24 months in 25 percent of the women who had a living child, despite a stated desire by 42 percent of the women for delaying or preventing the current pregnancy.

\section{Future desired fertility and FP intentions:}

- Ninety percent of women expecting their first child and 11 percent of those expecting a second or higher birth order child stated they wanted to have another child after the current birth; the majority wished to wait at least two years. The stated preferred waiting period of three to four years is in all probability more a reflection of media messages than of women's real attitudes.

- Of the women who preferred to wait at least two years before having another child, 44 percent stated they intend to use a FP method. Of those women who did not want more children, only 68 percent stated they intended to use a FP method.

- When asked where they would obtain FP methods and advice, the large majority of respondents, both men and women, stated they would go to ESIC.

\section{Gender roles and decision-making:}

- Almost all women and men stated that they would like to attend ANC services jointly. Two-third of the women even wished to have their husbands nearby during a physical exam and labor and birthing, as did three-fourth of the men.

- More than 50 percent reported some inter-spousal communication on issues related to maternity care, delivery plans and family planning. Decision-making on reproductive matters were usually taken jointly, but when it was one spouse who took the decision it was almost always the husband.

- Thirty nine percent of both spouses stated their intention to use FP while 44 percent were discordant on using FP after the birth of this baby.

- One fifth of the women reported having ever experienced any violence from their spouse.

\section{Reproductive health knowledge:}

- Reproductive health knowledge was low but men appeared to know more than their spouses. This difference may be explained by husbands' higher educational level and exposure, by virtue of their working outside the home, and also to media/IEC.

- Although most men had heard of HIV/AIDS, most women had not, and both genders possessed low specific knowledge of this disease. STI knowledge was even lower.

- Women, and to a lesser extent men, had very low knowledge of danger signs in pregnancy, birth and immediate postpartum.

\section{Presence of STI related symptoms:}

- In the ESIC served population of married, low parity couples a very low reporting of risky behaviors was noted in both men and women. However, a not negligible 9 percent of men reported having had burning during urination or urethral discharge in the last six months preceding the survey. Only two-third of men reporting the above symptoms sought any treatment. Of those who sought treatment, only 14 percent said spouses were also treated, 65 percent stopped having sex during treatment and 10 percent used condoms during intercourse. 
A post-intervention survey is being conducted between September 2001 and December 2002 with the same couples. The interviews are being held at home six months after the birth of the child to assess any changes in knowledge, attitudes, perceptions and actual behaviors related to the above issues. 


\section{TABLE OF CONTENTS}

I Introduction 1

Study collaboration with ESIC 1

Study design 2

Sample selection 3

II Description of Study Participants: Comparison of Control and Intervention Groups 4

General characteristics 4

Socio-demographic profile of respondents 6

Pregnancy histories of women from the intervention and control groups 7

Perceptions on the timing of the current pregnancy 8

III Comparing Pregnant Women's and their Husbands' STI and HIV/AIDS Related Knowledge, Attitudes, Past Behaviors and

Post Pregnancy Intentions

STI and HIV/AIDS knowledge, self-reported symptoms and care seeking

Heard of STIs and HIV/AIDS 11

Knowing STIs symptoms in men $\quad 11$

Knowledge of significance of pain/burning with urination in men 11

Significance of genital ulcer/sore (men or women) 11

$\begin{array}{ll}\text { Knowledge of STI protective behaviors } & 12\end{array}$

Risk behaviors for HIV/AIDS 12

Specific knowledge on STI and HIV/AIDS items (when prompted with specific STI and HIV/AIDS questions) 13

Self-reported symptoms of STIs in men and women 13

Symptoms of urethritis 13

Symptoms of genital ulcers/sore $\quad 14$

Assessment of the risk of STI and HIV/AIDS 14

$\begin{array}{ll}\text { IV Condom Knowledge and Use } & 14\end{array}$

$\begin{array}{ll}\text { Knowledge on dual protection from condoms } & 14\end{array}$

Knowledge of where to obtain condoms $\quad 15$

Condom use with spouse $\quad 15$

Intention to use condoms in the next 12 months 15 
MiM intervention for improving family planning knowledge and practices

Knowledge of benefits of child spacing

Knowledge of fertile days in woman's menstrual cycle

Knowledge that the combined oral contraceptive is less appropriate for breastfeeding women in the first six-months postpartum 17

$\begin{array}{ll}\text { Knowledge of contraceptive action of breastfeeding } & 18\end{array}$

$\begin{array}{ll}\text { Timing of birth and family size } & 18\end{array}$

Current birth spacing 18

$\begin{array}{ll}\text { Timing of next birth } & 19\end{array}$

Past use of contraception and future intentions $\quad 19$

$\begin{array}{ll}\text { Desire for current pregnancy } & 20\end{array}$

$\begin{array}{ll}\text { Desire for more children } & 21\end{array}$

Family planning intentions among women and men who wish to have more children 21

Preferred source to obtain their chosen FP method 22

Source of family planning information/advice 22

$\begin{array}{ll}\text { VI Child Health } & 22\end{array}$

Immunization of the youngest living child 23

Person responsible for bringing the child for immunization 23

Intention to breastfeed exclusively 23

$\begin{array}{lll}\text { VII Pregnancy Care } & 24\end{array}$

Reasons for attending the antenatal clinic according to women and their husbands 24

Views on harmful and healthy practices during pregnancy 24

Knowledge of danger signs during pregnancy and postpartum $\quad 25$

VIII Male Involvement and Spousal Communication 25

Men's role in maternity and its importance $\quad 25$

Male involvement and spousal communication data $\quad 26$

Presence of husbands at the dispensaries 26

Husband's help during the maternity process $\quad 27$

Husbands' assistance in an emergency $\quad 27$

$\begin{array}{ll}\text { Spousal communication and consultation } & 27\end{array}$

Spousal abuse, perceptions and prevalence 28

$\begin{array}{ll}\text { IX Clinic Services } & 29\end{array}$

Impact of the intervention at the clinics 29

Whether women and men felt welcome at the clinics 29

$\begin{array}{ll}\text { Seeking advice on family planning } & 29\end{array}$ 
$\begin{array}{lll}X & \text { Summary and Discussion } & 30\end{array}$

Pregnancy history $\quad 32$

Unmet family planning need $\quad 32$

Future desired fertility and family planning intentions $\quad 32$

Gender roles and decision-making 33

Reproductive health knowledge $\quad 34$

STI symptoms $\quad 34$

$\begin{array}{ll}\text { References } & 36\end{array}$ 


\section{List of Tables}

$\begin{array}{lll}2.1 & \text { Background characteristics of respondents } & 6\end{array}$

$\begin{array}{lll}2.2 & \text { Pregnancy history by number of living children } & 8\end{array}$

2.3 Age of the youngest child among women who had at least one living child

2.4 Women reported using family planning at the time of conception 9

2.5 Women's intention to have another child after the birth of the index pregnancy

3.1 Men and women's knowledge of HIV/AIDS protective behaviors

3.2 Men and women's knowledge about the modes of transmission of HIV/AIDS

3.3 Men and women's agreement with the following statements on ways to prevent or spread STIs and HIV/AIDS

5.1 Men and women's perception on benefits of child spacing

5.2 Breastfeeding and prevention of pregnancy: Duration of protection, and conditions under which breastfeeding are not effective in preventing pregnancy

5.3 Past use and intention to use family planning in the future among men and women

5.4 Desire for another child after the birth of index pregnancy among men and women

5.5 Men and women's intention to use a family planning method after this pregnancy by their intention to have another child

6.1 Person who took the youngest living child for immunization

7.1 Men and women's reported reasons for the importance of antenatal care

7.2 Women and men's perceptions on some harmful and beneficial practices during pregnancy

7.3 Women and men's knowledge on danger signs during pregnancy 
8.1 Women and men's perception on justification for physical/emotional Violence

9.1 Women and men's report on any informational materials received at the antenatal clinic

\section{List of Figures}

$\begin{array}{lll}\text { Figure 1: } & \text { Pregnancy histories of control and intervention group women } & 7\end{array}$

Figure 2: $\quad$ Women's perception about the timing of current pregnancy 9

Figure 3: Women and men's desire for current pregnancy 20 


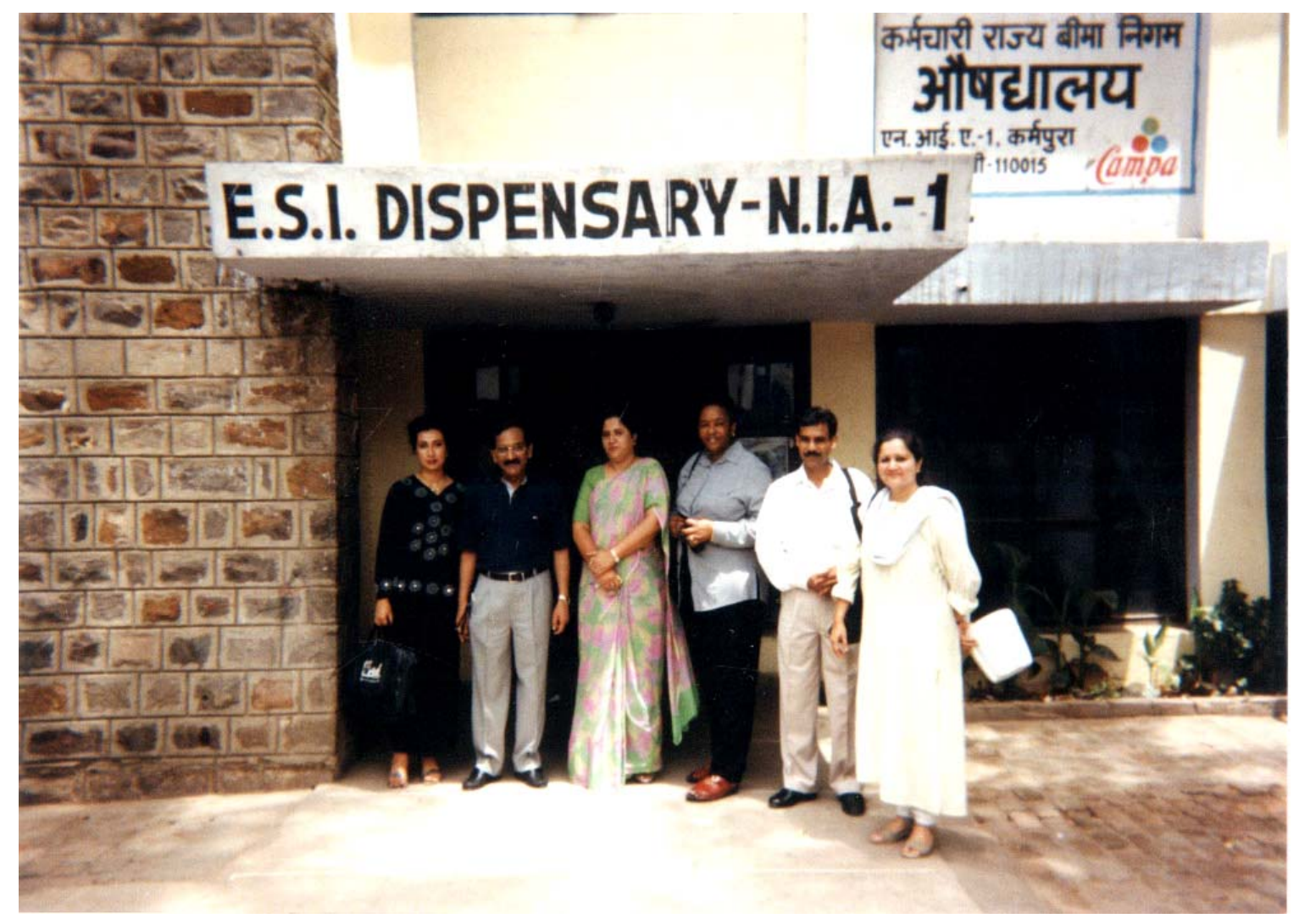

\section{INTRODUCTION}

The Population Council's FRONTIERS in Reproductive Health Project is collaborating with the Employees' State Insurance Corporation (ESIC) of India on the Men in Maternity Study (MiM). This is an Operations Research Study designed to assess the impact of male involvement on couples' reproductive health, specifically their use of postpartum family planning and STI preventive knowledge and practices. This objective is being met through involving men in their wives' antenatal and postpartum care in a clinic setting. This report describes the results of the pre-intervention survey designed to assess baseline characteristics of the study population.

\section{Study Collaboration with ESIC}

Employees working in industries in the private sector, who earn less than Rs. 6500.00 per month, are obligated by an Act of Parliament to be enrolled in the ESIC. With contributions from employers, employees and the State government, the ESIC Delhi provides care in sickness, maternity and employment injury through primary, secondary and tertiary level facilities. The workers' immediate families are also covered under this social security scheme. ESIC operates five hospitals and 34 dispensaries in Delhi. The 
ESIC in Delhi was selected as the setting for this OR study because of the large lowincome population it serves, its large male clientele, as well as the potential for up-scaling in such a large organized health care delivery system.

\section{Study Design}

The MiM project uses a quasi-experimental study design with three ESIC dispensaries functioning as Intervention sites and three functioning as Control sites. With training and implementation assistance provided by the Population Council, doctors, ANMs and laboratory assistants at the intervention sites are assisted in integrating family planning and STI related services into a new maternity-counseling component at existing weekly antenatal and immunization clinics. In addition, assistance has been provided to ensure that all pregnant women are screened for Syphilis. A detailed description of the intervention is available in Research Update No.2 (April 2002).

A Pre-intervention and a Postintervention Survey will be used to evaluate the effectiveness of these interventions. The survey design includes, interviewing the pregnant women at control sites and interviewing the pregnant women and their husbands at intervention

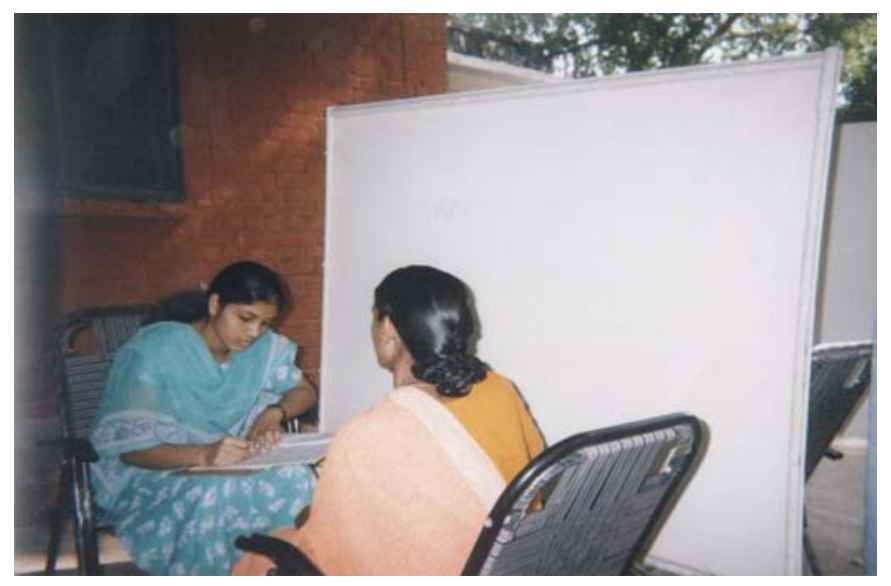
sites during their early visits to the clinic for antenatal care (ANC). The post intervention surveys will interview couples separately, from both control and experimental groups in their homes. The two consecutive surveys, termed "Control Pre. Survey", and "Intervention Pre. Survey" have been conducted and Post-intervention surveys are currently underway. This report describes the findings of the Pre- Surveys.

The nine key hypotheses of this study are as follows:

1. Exposure to the intervention will have a positive effect on men and women's knowledge of family planning and contraceptive practices at six months postpartum.

2. Exposure to the intervention will have a positive effect on men and women's STI preventive behaviors at six months postpartum. 
3. Exposure to intervention will increase service providers and clients' knowledge of the dual protection from STIs and pregnancy that is provided by condoms.

4. Exposure to the intervention will have a positive effect on female syphilis testing and appropriate management, and treatment of male urethritis and male and female genital ulcer disease.

5. Exposure to the intervention will have a positive effect on inter-spousal communication and support on reproductive health matters.

6. Exposure to the intervention will have a positive effect on selected indicators of infant health (e.g., immunizations, breastfeeding practices).

7. Exposure to the intervention will have a positive effect on the clients' and providers' satisfaction with antenatal and postpartum care.

8. The experimental intervention will produce the hypothesized results in a costeffective manner; both in terms of its marginal cost increases as well as any additional opportunity costs that are incurred for the new services.

9. Women in the experimental group will be more likely to recognize pregnancy and postpartum danger signs and adopt timely and appropriate care seeking if they occur, than women in the control group.

\section{Sample Selection}

The three eligibility criteria used were determined by the need (at the Intervention dispensaries) for clients to be able to have the opportunity to use the new integrated services. All pregnant women attending the ANC were screened for the study within the time period and selected if they met the following criteria:

- The woman should be between 10 to 26 weeks of gestation.

- She is likely to be present in Delhi at the same residential address at six months postpartum.

- She consents to participate in the study/be interviewed and agrees to interviewers contacting her husband to seek his participation after being fully informed about the study and read out the informed consent statement in the questionnaire.

The surveys used structured questionnaires for women and men designed for the purpose. The total sample size estimated was 450 women at the control clinics and 450 at the intervention clinics. Approximately 36 percent of the women met the eligibility criteria on any ANC clinic day. The large number of repeat visits for ANC and women first visiting the clinic after 26 weeks of pregnancy were the two main reasons for noneligibility. Actual refusals to participate in the study for other reasons were small (less than 2 percent). Women continued to be enrolled until the sample size was met. In the Pre intervention surveys, the data was collected from 1067 pregnant women (486 women from control sites and 581 women from intervention sites) from all the six selected ESIC 


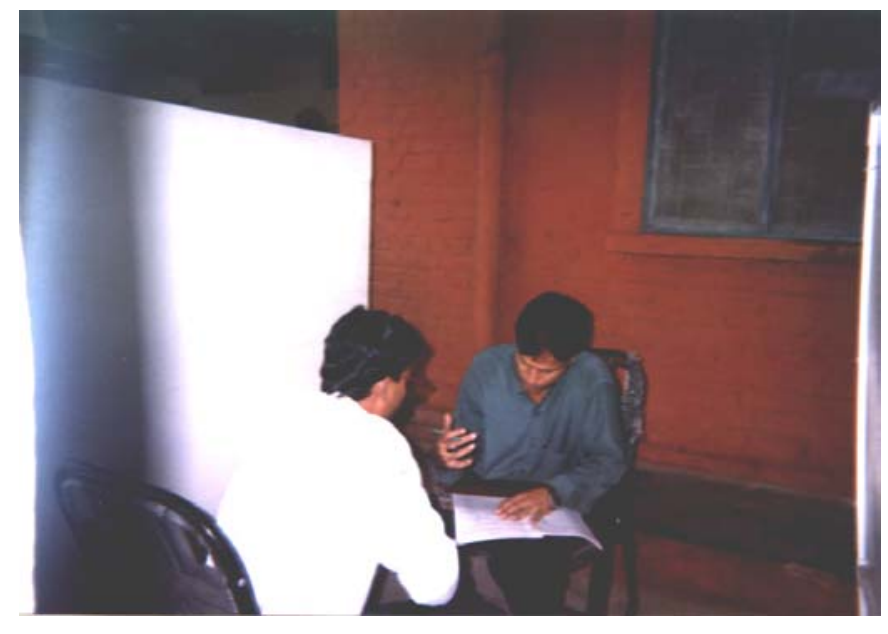

dispensaries during November 2000

to November 2001. This long enrollment period was required as ANCs were held only once (four dispensaries) or twice a week (in two dispensaries). In the experimental dispensaries, 488 (84 percent of women interviews) husbands of pregnant women were also

interviewed separately along with the women survey. None of the women refused to allow their husband's participation. Almost all the husbands belonging to the remainder 16 percent did not accompany their wives during their ANC visits despite repeated invitations given through their wives until one month after the female interviews in the dispensaries were completed. These husbands therefore couldn't be contacted for interview even though their wives had consented to her husband's participation in the study. These remaining 16 percent husbands will be contacted and may be interviewed at home in the postpartum period if their wife and they agree to be interviewed.

\section{DESCRIPTION OF STUDY PARTICIPANTS: COMPARISON OF CONTROL AND INTERVENTION GROUPS}

This section describes the study population and compares the general characteristics of women from the intervention and control sites in order to establish comparability of the two study groups.

\section{General Characteristics}

The MiM study population was defined by the fact that the study was conducted in Delhi, the capital of India, and that ESIC, an urban insurance scheme provider, catered to this low-income worker population and their families in the organized sector. Many of the insured persons have recently migrated to Delhi and tend to live in crowded, low-income residential areas or slums with narrow streets and open drains, Families most often live in a single, poorly ventilated room. 
A comparison of the characteristics of the intervention and control groups showed that their general background characteristics were similar. All the respondents of the survey reported being currently married and living with their spouse and children. Most women did not work outside the home (92 percent intervention, 89 in the control). Their living arrangements revealed that about half of the women lived with their husbands in a nuclear family (62 percent and 55 percent of the respondents in the control and intervention dispensaries, respectively) the remaining (38 percent and 44 percent) respondents lived in Delhi with their husbands and other family members. Only two respondents in the control dispensaries and three respondents in the intervention dispensaries said that they usually lived away from their husbands since they were responsible to look after their elderly parents-in-law in another location.

Information was collected on household arrangements and facilities in the home in order to assess the socio-economic status of the respondents. The data revealed similarity in the control and intervention groups. Eighty three percent of the respondents from the control group and 80 percent from the intervention group lived in permanent (Pucca) houses built with brick and cement. Forty percent of the women reported that the family owned their houses (39.9 percent from control group and 41.7 percent from intervention group) while 60 percent women reported that they lived in rented accommodation or houses provided by an employer. Sixty six percent of women from the control group and 71 percent of women from the intervention group reported that there was only one sleeping room in their household and 82 percent of women from both the groups reported that three or more members lived in the household. These statistics reflect the crowded conditions in most homes.

The proportion of households with electricity ranges from 90 percent in the control dispensaries to 95 percent in the intervention dispensaries. Around 77 percent of the households from both the control and intervention groups had running water inside the house. A substantial variation was observed in terms of availability of toilet inside the house. The proportion ranged from 68 percent in the intervention dispensaries to 81 percent in the control dispensaries and was representative of the availability of sewerage lines in the newly developed low income housing colonies. Telephones were present in the homes of 14 percent of the control group and 12 percent of the intervention group. 
Questions were asked regarding possession of few selected durable goods. The majority of the households had access to a television or a radio, 79 percent of the control group and 83 percent of the intervention group reported having television or radio. The most common mode of transport owned by the household were bicycles (43 percent in both the groups), followed by a motorcycle or scooter (13 and 11 percent in the control and intervention dispensaries, respectively) and less than 1 percent mentioned some other vehicle (1.6 and 0.7 percent in the control and intervention dispensaries respectively).

\section{Socio-demographic Profile of Respondents}

Table 2.1: Background Characteristics of Respondents

\begin{tabular}{|c|c|c|c|}
\hline \multirow[t]{2}{*}{ Background characteristics } & \multicolumn{3}{|c|}{ Proportion of respondents } \\
\hline & \multirow{2}{*}{$\begin{array}{c}\text { Control } \\
\text { Female } \\
(\mathrm{n}=486)\end{array}$} & \multicolumn{2}{|c|}{ Intervention } \\
\hline & & $\begin{array}{r}\text { Female } \\
(\mathrm{n}=581)\end{array}$ & $\begin{array}{r}\text { Male } \\
(\mathrm{n}=488)\end{array}$ \\
\hline Age & & & \\
\hline Less than 20 & 7.6 & 7.1 & 0.2 \\
\hline $20-24$ & 53.9 & 48.7 & 15.2 \\
\hline $25-29$ & 29.0 & 34.8 & 47.3 \\
\hline 30 and above & 9.4 & 9.5 & 37.3 \\
\hline Education & & & \\
\hline Illiterate & 33.1 & 35.6 & 7.6 \\
\hline Up to 5 years schooling & 3.7 & 4.0 & 14.1 \\
\hline $6-10$ years schooling & 32.3 & 34.1 & 48.6 \\
\hline More than 10 years schooling & 15.2 & 15.1 & 29.7 \\
\hline Working for money & 11.5 & 7.7 & 99.4 \\
\hline Currently married & 100.0 & 100.0 & 100.0 \\
\hline Living arrangement & & & \\
\hline Only with spouse & 61.5 & 54.9 & 55.8 \\
\hline Without spouse with other family members & 0.4 & 0.5 & 5.5 \\
\hline Living with spouse and other family members & 38.1 & 44.6 & 38.7 \\
\hline Duration of marriage & & & \\
\hline Less than 2 years & 16.5 & 15.0 & 15.2 \\
\hline $2-4$ & 29.8 & 26.0 & 27.0 \\
\hline $5-7$ & 25.5 & 25.8 & 27.3 \\
\hline $8-10$ & 16.5 & 18.2 & 16.0 \\
\hline $11 \&$ above & 11.7 & 15.0 & 14.5 \\
\hline Husband away at night & & & \\
\hline Less than a week per month & 91.4 & 83.3 & 85.9 \\
\hline $1-2$ weeks per month & 7.6 & 13.6 & 10.7 \\
\hline More than two weeks per month & 0.8 & 3.1 & 3.0 \\
\hline Other responses & 0.2 & 0.0 & 0.4 \\
\hline
\end{tabular}


An analysis of the general characteristics of the Intervention and Control group's women and the Intervention group's husbands showed that there was considerable variation within groups. However, the overall proportions were similar across the intervention and control groups. Men and women tended to respond similarly in the intervention group. Table 2.1 details this comparison.

\section{Pregnancy Histories of Women from the Intervention and Control Groups}

Comparisons of pregnancy histories of the intervention and control groups revealed that the two groups were similar. The proportion that was pregnant for the first time was 29 percent in the control group and 23 percent in the intervention group. Similar proportions between the two groups reported having had an induced abortion ( 7 percent) or a miscarriage (26 percent) in the past.

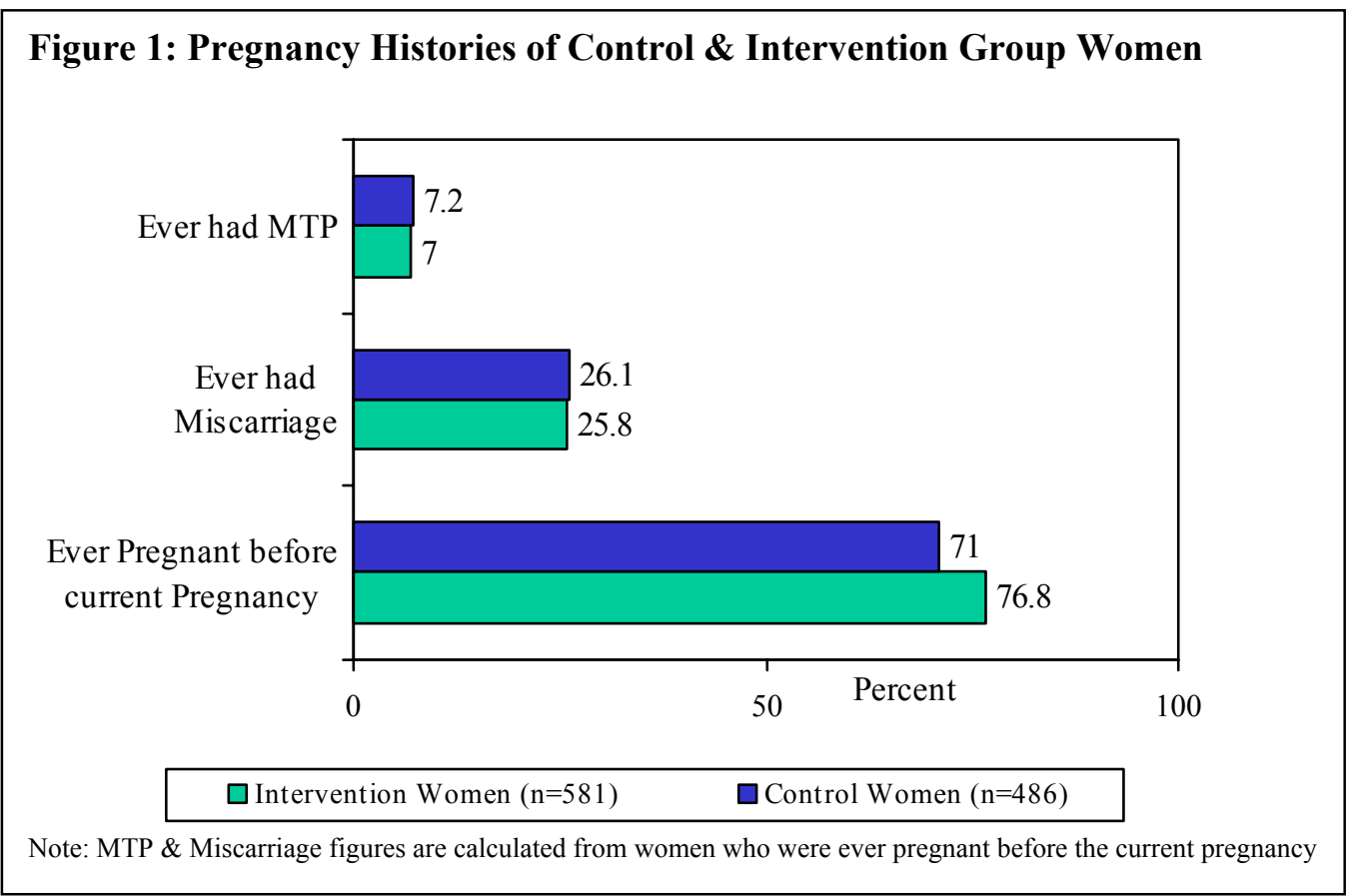

Further comparisons between the intervention and control groups on the number of living children showed a statistically significant difference on the mean number of living children, 0.92 in the intervention and 1.10 among the control group $(\mathrm{p}<.05)$ however, in actual terms this represents an average of one living child and there was a similar trend in the samples across parities as illustrated in Table 2.2. 
Table 2.2: Pregnancy History by Number of Living Children

\begin{tabular}{|l|r|r|r|r|r|r|}
\hline \multicolumn{2}{|c|}{ Total number of living children } & \multicolumn{2}{|c|}{ Ever had miscarriage } & \multicolumn{2}{|c|}{ Ever had MTP } \\
\hline $\begin{array}{l}\text { Living } \\
\text { Children }\end{array}$ & $\begin{array}{r}\text { Control } \\
(\mathrm{n}=486)\end{array}$ & $\begin{array}{r}\text { Intervention } \\
(\mathrm{n}=581)\end{array}$ & $\begin{array}{r}\text { Control } \\
(\mathrm{n}=90)\end{array}$ & $\begin{array}{r}\text { Intervention } \\
(\mathrm{n}=115)\end{array}$ & $\begin{array}{r}\text { Control } \\
(\mathrm{n}=25)\end{array}$ & $\begin{array}{r}\text { Intervention } \\
(\mathrm{n}=31)\end{array}$ \\
\hline None & 37.8 & 32.7 & 34.4 & 29.6 & 4.0 & 3.2 \\
1 & 39.3 & 36 & 44.4 & 38.3 & 40.0 & 48.4 \\
2 & 16.9 & 22.9 & 18.9 & 25.2 & 36.0 & 32.3 \\
3 & 4.9 & 5.9 & 1.1 & 5.2 & 12.0 & 9.7 \\
$4+$ & 1.0 & 2.6 & 1.2 & 1.7 & 8.0 & 6.4 \\
\hline
\end{tabular}

Of the women who had at least one living child, the age of youngest living child showed that a large number of women had a child younger than two years. In fact, the median age of the youngest child was two years. Table 2.3 demonstrates that the difference between the two groups is in the fact that a larger number of women in the intervention group reported that they were pregnant again with the youngest child less than one year old and fewer after 4 years. It is not clear why there is this shift in proportions between the two groups.

Table 2.3: Age of the Youngest Child among Women who had at least One Living Child

\begin{tabular}{|l|r|r|}
\hline Age of the youngest child & $\begin{array}{r}\text { Control } \\
(\mathrm{n}=303)\end{array}$ & $\begin{array}{r}\text { Intervention } \\
(\mathrm{n}=391)\end{array}$ \\
\hline Under 12 months old & 1.0 & 6.1 \\
12 to 17 months old & 7.9 & 10.2 \\
18 to 23 months old & 16.2 & 12.0 \\
24 to 48 months old & 55.7 & 57.7 \\
Above 4 years & 19.5 & 13.5 \\
\hline
\end{tabular}

\section{Perceptions on the Timing of the Current Pregnancy}

A comparison between the intervention and control group (see Figure 2) showed that among first time pregnant women, most women wanted the pregnancy at the time, however in those with at least one other child 24 and 27 percent respectively would have wanted to delay the pregnancy and at least 12 and 13 percent stated that they had not wanted any more children. However their desire for delaying or not having this pregnancy was not necessarily matched by their use of family planning method in the past. Almost none of the primigravida women reported using a method of contraception at the time they became pregnant while 9.3 in the control and 7.6 percent in the intervention group, who have at least one child were using a method at the time of conception. 


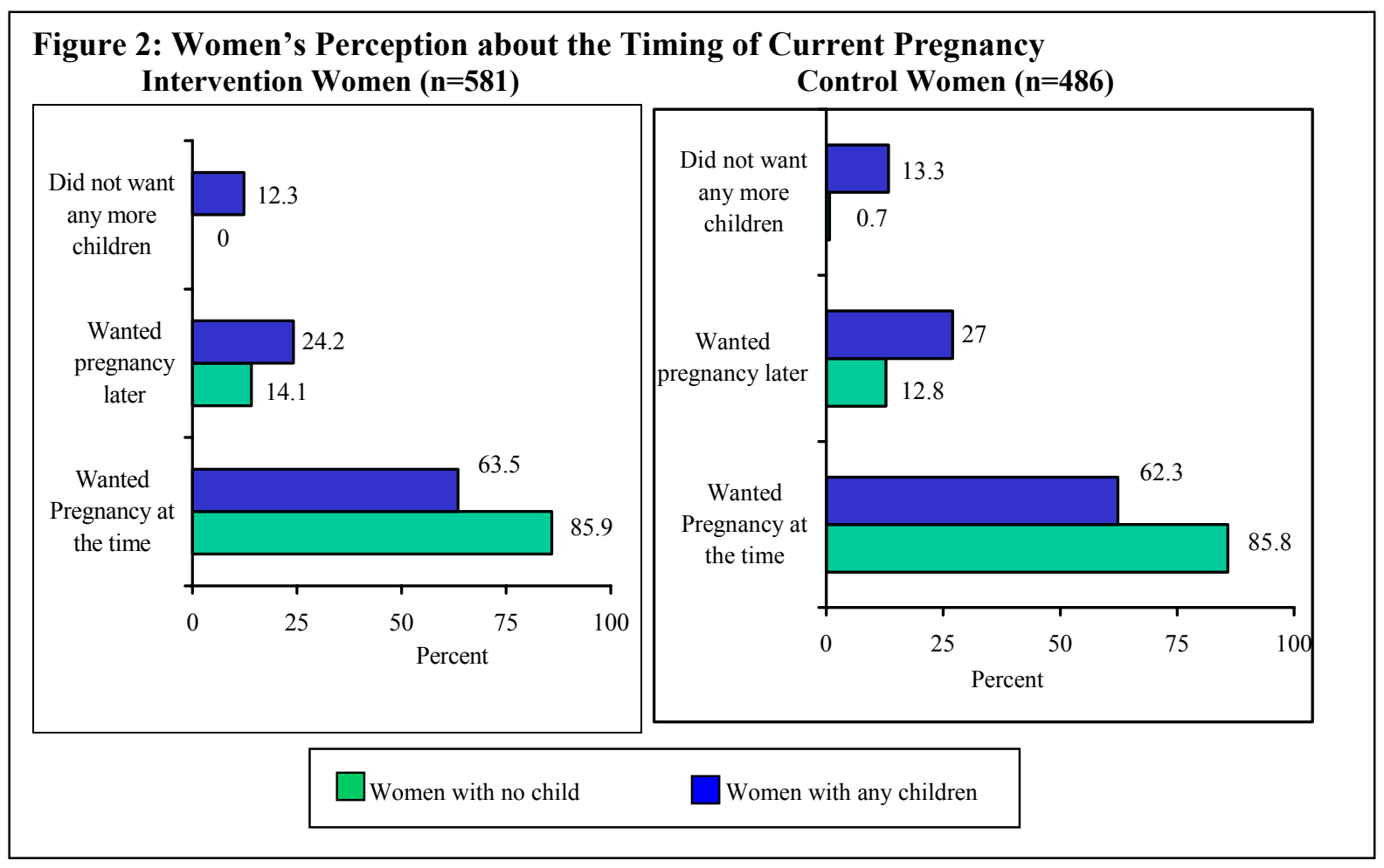

Table 2.4: Women Reported Using Family Planning at the Time of Conception

\begin{tabular}{|l|r|r|r|r|}
\hline \multirow{2}{*}{ F.P. Use } & \multicolumn{2}{|c|}{ Control } & \multicolumn{2}{c|}{ Intervention } \\
\cline { 2 - 5 } & $\begin{array}{r}\text { Primigravida } \\
(\mathrm{n}=141)\end{array}$ & $\begin{array}{r}\text { Multigravida } \\
(\mathrm{n}=345)\end{array}$ & $\begin{array}{r}\text { Primigravida } \\
(\mathrm{n}=135)\end{array}$ & $\begin{array}{r}\text { Multigravida } \\
(\mathrm{n}=446)\end{array}$ \\
\hline $\begin{array}{l}\text { Using FP method at time } \\
\text { of conception }\end{array}$ & & & & \\
Yes & 0.7 & 9.3 & 0.7 & 7.6 \\
& & & & \\
FP Method mentioned & 100.0 & 50.0 & 100.0 & 47.1 \\
Condoms & 0 & 28.1 & 0 & 41.2 \\
Pills & 0 & 9.4 & 0 & 8.8 \\
IUD & 0 & 12.5 & 0 & 2.9 \\
Other & $\mathbf{1}$ & $\mathbf{3 2}$ & $\mathbf{1}$ & $\mathbf{3 4}$ \\
\hline Total women used FP & & & & \\
\hline
\end{tabular}

From the analysis of contraceptive use at the time of conception, it is clear that quite a few women were incorrectly or inconsistently using the contraceptive method, as failure rates are much higher than in conditions of consistent and correct use. 
Table 2.5: Women's Intention to have Another Child after the Birth of the Index Pregnancy

\begin{tabular}{|l|r|r|r|r|}
\hline \multirow{2}{*}{ Want to have another child } & \multicolumn{2}{|c|}{ Control } & \multicolumn{2}{|c|}{ Intervention } \\
\cline { 2 - 5 } & $\begin{array}{r}\text { Women } \\
\text { with no } \\
\text { Child } \\
(\mathrm{n}=184)\end{array}$ & $\begin{array}{r}\text { Women with } \\
\text { One or more } \\
\text { Children } \\
(\mathrm{n}=302)\end{array}$ & $\begin{array}{r}\text { Women } \\
\text { with no } \\
\text { Child } \\
(\mathrm{n}=190)\end{array}$ & $\begin{array}{r}\text { Women with } \\
\text { One or more } \\
\text { Children } \\
(\mathrm{n}=391)\end{array}$ \\
\hline Yes, without sex preference & 84.8 & 8.3 & 89.5 & 11.0 \\
Yes, if this baby a boy & 2.2 & 2.3 & 0.5 & 2.0 \\
Yes, if this baby a girl & 2.2 & 11.9 & 1.6 & 11.0 \\
No/No more & 8.7 & 73.2 & 7.4 & 70.1 \\
Undecided/ Don't Know & 2.2 & 4.3 & 1.1 & 5.6 \\
\hline
\end{tabular}

Most women with no children wanted another child suggesting that the two-child norm exists. However there were 8.7 percent of women who did mention that they only wanted one child. Preference for a boy child, not apparent in the first child, became far more pronounced among women with at least one child, especially if they already had a daughter.

\section{COMPARING PREGNANT WOMEN'S AND THEIR HUSBANDS' HIV/AIDS AND STI RELATED KNOWLEDGE, ATTITUDES, PAST BEHAVIORS AND POST PREGNANCY INTENTIONS}

A sound knowledge base is imperative for couples to adopt healthy care-seeking behaviours. This section compares and examines men and women's knowledge on STIs and HIV/AIDS related subjects.

\section{STI and HIV/AIDS Knowledge, Self-reported Symptoms and Care Seeking}

For STIs, the MiM intervention chose to focus on early identification and syndromic management of male urethritis and male and female genital ulcer diseases. Vaginal discharge was not included because it has a very low predictive value that results in stigmatisation and over-treatment of women who are free of an STI as well as significant under treatment of women with an infection but who are asymptomatic. Additionally, MiM included universal syphilis RPR testing of pregnant women and management of positive cases, including husband treatment, BCC and condom use promotion and provision. HIV/AIDS preventive education and protective behaviours are included in the STI counselling component. 


\section{Heard of STIs and HIV/AIDS}

The percentage of women and men aware of HIV/AIDS was higher than the percentage aware of STIs. About 70 percent of women and 31 percent of men had never heard of STIs or hidden illness whereas about half of the women and only 7 percent of men had never heard of the disease called HIV/AIDS. This implied very low knowledge and that approximately twice as many men than women had heard of these diseases. Recent vigorous mass media campaigns on HIV/AIDS could account for the fact that more people reported having heard of HIV/AIDS than other STIs.

\section{Knowing STIs Symptoms in Men}

In order to understand whether respondents were aware of symptoms of STIs, they were asked if they knew any symptom of STIs in men and women, separately. Significantly only about one-fifth of men and 1 percent of women could mention any symptoms of STIs in men (78.5 percent of men and 99 percent of women said they did not know any symptoms of STIs in men). Only 3.3 percent men said that pain or burning with urination, 2.5 percent said that urethral discharge and 3.7 percent said that sores or ulcers were manifestations of STIs in men.

\section{Knowledge of Significance of Pain/Burning with Urination in Men}

When asked specifically, what pain or burning sensation occurring during urination meant, more than half of men (51 percent) stated that it indicated an STI or a health problem that needed medical consultation. Among women only 8 percent identified them as symptoms of disease.

\section{Significance of Genital Ulcer/Sore (Men or Women)}

When asked the significance of a genital sore or ulcer in a man or a woman, 57 percent of men identified it as a disease and 37 percent stated they did not know. To the same question, only 2.2 percent of women stated that a genital sore or ulcer indicated a disease and 89 percent did not know the significance. 


\section{Knowledge of STI Protective Behaviors}

Men and women who stated they had heard of HIV/AIDS were asked if they knew ways to prevent infection. Spontaneous responses showed a range of protective measures with men mentioning a wider ranger than women. Table 3.1 presents the frequently mentioned ways of protecting oneself.

Table 3.1: Men and Women's Knowledge of HIV/AIDS Protective Behaviours

\begin{tabular}{|l|r|r|}
\hline Protective ways & $\begin{array}{r}\text { Men } \\
(\mathrm{n}=458)\end{array}$ & $\begin{array}{r}\text { Women } \\
(\mathrm{n}=283)\end{array}$ \\
\hline Stay faithful to spouse & 25.2 & 53.7 \\
Encourage spouse to remain faithful & 2.2 & 9.5 \\
Use condoms & 37.1 & 23.3 \\
Avoid sharing razors/needles & 35.8 & 45.2 \\
Avoid sex with prostitutes & 35.2 & 1.1 \\
Avoid multiple sex partners & 18.3 & 13.1 \\
Others & 3.8 & 4.0 \\
Don't know & 13.5 & 21.9 \\
\hline
\end{tabular}

\section{Risk Behaviors for HIV/AIDS}

When asked what behaviors could spread HIV/AIDS, a large proportion was able to mention one or two ways correctly. Of the men and women who had heard of the disease, 84 percent men and 82 percent women, respectively stated sexual intercourse, 47 percent of men and 48 percent of women said sharing blades/needles and 20 percent of men and 35 percent of women revealed blood transfusion, as ways of acquiring HIV/AIDS.

Table 3.2: Men and Women's Knowledge about the Modes of Transmission of HIV/AIDS

\begin{tabular}{|l|r|r|}
\hline \multirow{2}{*}{$\begin{array}{l}\text { Modes of HIV/AIDS } \\
\text { transmission }\end{array}$} & \multicolumn{2}{|c|}{ Percent agreed with statements } \\
\cline { 2 - 3 } & $\begin{array}{r}\text { Men } \\
(\mathrm{n}=456)\end{array}$ & $\begin{array}{r}\text { Women } \\
(\mathrm{n}=285)\end{array}$ \\
\hline Sexual intercourse & 88.4 & 81.8 \\
Blood transfusion & 20.0 & 35.1 \\
Sharing blades/needles & 47.4 & 48.4 \\
Mother to baby & 5.7 & 5.0 \\
Others & 4.2 & 0.8 \\
Don't know & 10.1 & 18.6 \\
\hline
\end{tabular}




\section{Specific Knowledge on STI and HIV/AIDS Items (When prompted with specific STI and HIV/AIDS questions)}

In order to understand the perception of respondents on issues related to STIs and HIV/AIDS, respondents were then asked if they agreed or disagreed with specific (statements about) modes of prevention and spread of STIs and HIV/AIDS. Table 3.3 details their responses. Clearly, prompted responses were higher than unprompted responses.

Table 3.3: Men and Women's Agreement with the Following Statements on Ways to Prevent or Spread STIs and HIV/AIDS

\begin{tabular}{|l|r|r|}
\hline Statements on STIs/HIV/AIDS & $\begin{array}{r}\text { Men } \\
\text { percent } \\
\text { Agreed }\end{array}$ & $\begin{array}{r}\text { Women } \\
\text { percent } \\
\text { Agreed }\end{array}$ \\
\hline $\begin{array}{l}\text { Can a person get HIV/AIDS be getting injections with an infected } \\
\text { needle? }\end{array}$ & 95.4 & 92.2 \\
$\begin{array}{l}\text { Can a woman with HIV/AIDS transmit the virus to her baby through } \\
\text { breastfeeding? }\end{array}$ & 68.9 & 73.3 \\
Is there a test for HIV/AIDS? & 55.5 & 36.2 \\
\hline Respondents who have heard of HIV/AIDS & $\mathbf{4 1 1}$ & $\mathbf{2 3 2}$ \\
\hline $\begin{array}{l}\text { Is it possible to have a sexually transmitted diseases including HIV / } \\
\text { AIDS and look healthy? }\end{array}$ & 37.3 & 30.4 \\
$\begin{array}{l}\text { Can people protect themselves from STI/ HIV / AIDS by using a } \\
\text { condom correctly every time they have sex? }\end{array}$ & 83.8 & 56.5 \\
$\begin{array}{l}\text { Can people protect themselves from STI/ HIV / AIDS by having only } \\
\text { one uninfected sex partner? }\end{array}$ & 94.5 & 86.6 \\
$\begin{array}{l}\text { Can people protect themselves from STI/ HIV / AIDS by abstaining } \\
\text { from sexual intercourse? }\end{array}$ & 75.5 & 67.5 \\
$\begin{array}{l}\text { Can a pregnant woman infected with a sexually transmitted disease or } \\
\text { HIV/AIDS transmit the disease to her unborn child? }\end{array}$ & 80.1 & 83.4 \\
\hline Respondents who had knowledge on STI/HIV/AIDS & $\mathbf{4 5 8}$ & $\mathbf{2 8 3}$ \\
\hline
\end{tabular}

\section{Self-Reported Symptoms of STIs in Men And Women}

Men and women were asked if they had had STI related symptoms in the past six months. Very few reported symptoms.

\section{Symptoms of Urethritis}

Nine percent of men (45) stated they had had pain and/or burning with urination in the last six months. Women were usually not aware that their husband was having this problem. Only 1.4 percent of women (15) stated that their husband had had symptoms of urethritis. 
Of the above 9 percent symptomatic men, 66 percent (29 men) sought advice from either an ESIC or private doctor.

\section{Symptoms of Genital Ulcers/Sore}

Seven men (1.4 percent) and seven women (1.2 percent) reported having had an ulcer on their genitals in the last six months. Four of the men and all of the women reporting a symptom sought advice from a physician.

\section{Assessment of the Risk of STI and HIV/AIDS}

The perception of risk for acquiring an STI and/or HIV/AIDS was low among men and women. Ninety two percent of men and 34 percent of women clearly mentioned they had no chance of becoming infected. However, about 60 percent of women did not know about chances of contracting infections. This was probably due to the low awareness levels about these infections among women. This low risk self-assessment is not unreasonable considering that, only two men and no women reported having had extramarital relations during the pregnancy.

\section{CONDOM KNOWLEDGE AND USE}

Condom knowledge, correct use, promotion and distribution are components of MiM. These are accomplished through couple and individual counselling, condom use demonstrations on a penis model to same-sex groups and new BCC materials (brochure for men and posters on clinic walls). Condoms were also offered to all clients in the antenatal and postpartum clinics.

\section{Knowledge on Dual Protection from Condoms}

Of the 458 men, and 298 women who knew about STIs/HIV/AIDS, 78 percent of men and 56 percent of the women respectively, correctly identified condoms as the method that could prevent against pregnancy, STIs and HIV/AIDS.

When asked an open question on what condoms were used for, 25 percent of men stated that they were used for pregnancy prevention, 4 percent reported STD prevention and 70 percent revealed protection from both. Of the women, 55 percent mentioned pregnancy 
protection, 1 percent said STDs protection and 24 percent reported protection from both pregnancy and STIs/HIV.

Though dual protection knowledge can be improved, there is an existing knowledge base. As with other knowledge components, women, less exposed to media, were less knowledgeable than men.

\section{Knowledge of Where to Obtain Condoms}

ESIC Hospital/clinic (61 percent men and 43 percent women), pharmacies (55 percent men and 19 percent women) and kiosks (49 percent men and 21 percent women) were the most frequently mentioned sources reported by respondents to obtain condoms.

\section{Condom Use with Spouse}

When specifically asked about having ever used condoms, 37 percent of men and 24 percent of women reported they had used condoms with their spouse but most used them inconsistently. Of those who had used condoms, 9 percent of men and 28 percent of women stated they had used them every time or most of the time they had sexual intercourse. Most had used them to prevent pregnancy and almost none had used them concurrently with another method. Of the men who had used condoms, 54 percent stated they had been the ones to decide to use and 42 percent reported that it was the couple's decision. Notably more men (11 percent) than women (6 percent) stated they had experienced problems using condoms.

\section{Intention to Use Condoms in the Next 12 Months}

Fifty nine percent of men and 29 percent of women stated they intended to use condoms with their spouse over the next year. In addition, 17 percent women reported that it was the husbands' decision. As seen earlier, there is such low self perception of risk of STIs that these figures are not remarkable. 


\section{FAMILY PLANNING KNOWLEDGE, ATTITUDES, PAST USE AND INTENTION TO USE AFTER THIS PREGNANCY}

\section{MiM Intervention for Improving Family Planning Knowledge and Practices}

The MiM intervention developed on the hypothesis that antenatal and six weeks postpartum couple counselling were appropriate times for improving couples' family planning knowledge and attitudes. It was hypothesized that the improved knowledge, coupled with providing clients the option of informed choice from a variety of methods in the postpartum period, would result in an increase in appropriate method use at six months postpartum, based on individual fertility goals and breastfeeding status.

Among the appropriate methods, Lactational Amenorrhoea Method (LAM) was neglected and under-emphasized in many programs; partly due to providers' ignorance of the LAM criteria and distrust of its effectiveness as a pregnancy preventive method. This was corrected during training of providers, and through supply of clearly illustrated posters on LAM in the intervention clinics.

Past research evidence revealed that when a client received a method of her or his choice, there was less likelihood of discontinuation compared to when the provider or another person made the selection. In the baseline data, information on pregnant women's and men's knowledge and attitudes on child spacing and family planning, past use and intention to use in the postpartum period, linked these with parity.

In the six-month postpartum survey the MiM study will document any increase in knowledge and more importantly family planning use comparing outcomes in the experimental group, exposed to the intervention, with the control group.

\section{Knowledge of Benefits of Child Spacing}

Since attitude towards birth spacing and perceptions regarding the benefits of birth spacing, to a large extent, influence the actual practice of family planning, the respondents were asked their opinion on the benefits of birth spacing.

The national family planning program's message to space children between two and four years apart was well understood and received by this population. There was widespread 
understanding and awareness that short spacing intervals were not good options. Only 9 percent men and 14 percent women stated that the ideal spacing should be less than two years. All the rest spoke of intervals more than two years. Additionally, 46 percent of women mentioned that spacing would benefit the health of the child.

Table 5.1: Men and Women's Perception on Benefits of Child Spacing

\begin{tabular}{|l|r|r|}
\hline Family Planning benefits and ideal spacing of births & $\begin{array}{r}\text { Men } \\
(\mathrm{n}=488)\end{array}$ & $\begin{array}{r}\text { Women } \\
(\mathrm{n}=581)\end{array}$ \\
\hline Perceived benefits (multiple options) & percent & percent \\
For the health of mother & 54.6 & 59.7 \\
For the health of baby & 63.5 & 45.6 \\
Age difference makes child care easier & 42.7 & 49.7 \\
Financial reasons & 20.6 & 21.5 \\
& & \\
Ideal age difference between two children & 8.8 & \\
Up to 2 years & 69.9 & 14.3 \\
2-4 years & 20.9 & 67.1 \\
More than 4 years & & 17.2 \\
\hline
\end{tabular}

\section{Knowledge of Fertile Days in Woman's Menstrual Cycle}

Knowledge of the fertile period was low among men and women. Half of the men stated there was a specific time in the cycle when a woman was more likely to conceive, but of these, only 5 percent men could state the correct days when the woman was fertile. Of the surveyed women, 84 percent did not know of such a time in the cycle. Of those who knew, 15 percent (12 out of 79 women) identified the fertile days correctly.

\section{Knowledge that the Combined Oral Contraceptive is Less Appropriate for Breastfeeding Women in the First Six Months Postpartum}

The WHO recommends not using combined oral contraceptive pills in the first six months postpartum in breastfeeding women because the estrogen hormone reduces milk quantity. Progesterone pills are not available in India. ESIC providers were aware of this and did not recommend oral pills to postpartum women. However, of the population surveyed, most people stated they did not know if there was a less appropriate FP method. Only 10 percent men and 3 percent women identified combined oral contraceptive pills as less appropriate for breastfeeding women in the first six months. 


\section{Knowledge of Contraceptive Action of Breastfeeding}

One of the principal BCC components of MiM was knowledge of best practices in terms of breastfeeding behaviours and the use of breastfeeding as a contraceptive method (LAM). The baseline survey showed that this knowledge was completely absent in the antenatal population served by ESIC before the implementation of the MiM intervention.

Table 5.2: Breastfeeding and Prevention of Pregnancy: Duration of Protection, and Conditions under which Breastfeeding are not Effective for Preventing Pregnancy

\begin{tabular}{|l|r|r|}
\hline Breast feeding and Prevention of Pregnancy & \multicolumn{2}{|c|}{$\begin{array}{c}\text { Proportion of } \\
\text { Respondents }\end{array}$} \\
\cline { 2 - 3 } & $\begin{array}{r}\text { Female } \\
\text { (n=581) }\end{array}$ & $\begin{array}{r}\text { Male } \\
(\mathbf{n = 4 8 8})\end{array}$ \\
\hline Can breastfeeding prevent a woman from getting pregnant? & 6.7 & 20.1 \\
Yes & 23.6 & 37.1 \\
No & 69.5 & 41.4 \\
Don't know & $\mathbf{n = 3 9}$ & $\mathbf{n = 9 8}$ \\
\hline Women/men who believe that breastfeeding can prevent pregnancy & & \\
\hline How long can breastfeeding prevent a woman from getting pregnant? & 10.3 & 12.2 \\
Less than 3 months & 10.3 & 32.7 \\
3-6 months & 12.8 & 29.6 \\
More than 6 months & 25.6 & 5.1 \\
As long as she breastfeeding / Indefinitely & 41.0 & 20.4 \\
Don't know & & \\
\hline Mentioned all the three conditions of LAM & 0.0 & 0.2 \\
\hline Yes
\end{tabular}

\section{Timing of Birth and Family Size}

In South Asian and many other developing countries, couples are expected to have their first child soon after marriage; and, in many, couples are expected to have at least two children before they considered delaying or preventing future fertility. In presenting the baseline data on previous use and intention to use family planning after the baby's birth, responses given by women and men who were expecting their first baby and those who had one or more living children have been compared.

\section{Current Birth Spacing}

The data from the baseline survey was analysed to see the time interval between the previously born child and the expected child among women who had an older living child. It can be concluded that, because the average gestation was six months when surveyed, previous children under the age of 21 months would be followed by a younger 
sibling's birth in less than two years. It is known that a birth interval of less than 24 months increased the risk of the infant's death two-fold.

Women who had one or more living children were asked for the age, in months of their youngest child. Despite their stated ideal spacing period, of the 391 women who had a living child, 10 percent of these children were 12 months old or less, 13 percent were 13 to 18 months old and a further 2 percent were between the ages of 19 and 21 months. Thus, 25 percent of the expected babies will have, based upon the age of their immediately older sibling, a two-fold risk of dying in infancy.

\section{Timing of Next Birth}

The survey asked men and women how long they wished to wait before having another child. Of those who stated they would like more children, 98 percent of both men and women reported they wished to wait two or more years before having another child, suggesting that intentions and practices were clearly not matched.

\section{Past Use of Contraception and Future Intentions}

Tubectomy was the most preferred method of FP after completion of family size. Oral pills, $\mathrm{Cu}-\mathrm{T}$ and condoms were methods of spacing preferred after the birth of the first child. The intention to use the intrauterine device $(\mathrm{Cu}-\mathrm{T})$ varied between the women without any living children (7.4 percent) and women with a living child/children (4.1 percent). Only one woman without any children had used the $\mathrm{Cu}-\mathrm{T}$ before the current pregnancy. The proportion that intended to use any method of contraception rose to 73 percent after two children.

Differences in report of family planning use between men and women centered mainly around the use of condoms where men mentioned condom use more often than women. When analysing intention to use a method after the birth of this child, more women mentioned female sterilization than men, while more men mentioned condoms than women, suggesting more women wanted a terminal method than men. 
Table 5.3: Past Use and Intention to Use Family Planning in the Future among Men and Women

\begin{tabular}{|c|c|c|c|c|c|c|}
\hline \multirow{3}{*}{\begin{tabular}{|} 
Ever Use \\
$\&$ \\
Intention to Use
\end{tabular}} & \multirow{2}{*}{\multicolumn{2}{|c|}{$\begin{array}{l}\text { Ever Used a FP } \\
\text { Method - Women } \\
\text { (25 percent of all } \\
\text { women have used a } \\
\text { method sometime) }\end{array}$}} & \multirow{2}{*}{\multicolumn{2}{|c|}{$\begin{array}{l}\text { Future Intention - } \\
\text { Women } \\
\text { (63.7percent of all } \\
\text { women intend to use) }\end{array}$}} & \multicolumn{2}{|c|}{$\begin{array}{l}\text { Ever Use and Future } \\
\text { Intention to use a FP } \\
\text { Method - Men }\end{array}$} \\
\hline & & & & & \multirow{2}{*}{$\begin{array}{c}\begin{array}{c}\text { Ever } \\
\text { Use }\end{array} \\
\text { All men } \\
(\mathrm{n}=488)\end{array}$} & \multirow{2}{*}{$\begin{array}{r}\text { Intention } \\
\\
\text { All men } \\
(\mathrm{n}=488)\end{array}$} \\
\hline & $\begin{array}{r}\text { Women } \\
\text { with No } \\
\text { child } \\
(\mathrm{n}=190)\end{array}$ & $\begin{array}{r}\text { Women } \\
\text { with at } \\
\text { least One } \\
\text { Child } \\
(\mathrm{n}=391)\end{array}$ & $\begin{array}{r}\text { Women } \\
\text { with No } \\
\text { child } \\
(\mathrm{n}=190)\end{array}$ & $\begin{array}{r}\text { Women } \\
\text { with at } \\
\text { least One } \\
\text { Child } \\
(\mathrm{n}=391) \\
\end{array}$ & & \\
\hline $\begin{array}{l}\text { Ever Used a FP Method } \\
\text { Intend to use after birth }\end{array}$ & 11.1 & 31.7 & 45.8 & 72.4 & 40.4 & 56.1 \\
\hline Method used/intended & & & & & & \\
\hline Tubectomy & 0.0 & 0.0 & 0.5 & 46.8 & $\begin{array}{l}0.0 \\
0.0\end{array}$ & $\begin{array}{r}41.1 \\
24\end{array}$ \\
\hline Vasectomy & 0.0 & 0.0 & 0.0 & 0.2 & $\begin{array}{r}0.0 \\
28\end{array}$ & $\begin{array}{r}2.4 \\
18.2\end{array}$ \\
\hline Condoms & $\begin{array}{l}7.4 \\
1.6\end{array}$ & $\begin{array}{l}17.4 \\
11.8\end{array}$ & $\begin{array}{r}6.3 \\
11.6\end{array}$ & $\begin{array}{l}3.3 \\
82\end{array}$ & $\begin{array}{l}28.7 \\
117\end{array}$ & $\begin{array}{l}18.2 \\
14.7\end{array}$ \\
\hline $\mathrm{Cu}-\mathrm{T}$ & 0.5 & 5.4 & 7.4 & 4.1 & 4.1 & 6.2 \\
\hline LAM & 0.0 & 0.0 & 0.0 & 0.2 & 1.0 & 0.0 \\
\hline Other modern methods* & 1.6 & 1.6 & 2.6 & 1.5 & 1.4 & 0.0 \\
\hline Not decided yet & & & 16.3 & 7.9 & & 11.3 \\
\hline Rhythm or safe period & 2.6 & 2.8 & 0.5 & 0.0 & 8.2 & 0.0 \\
\hline Withdrawal & 0.5 & 3.3 & 0.5 & 0.0 & 8.4 & 0.0 \\
\hline
\end{tabular}

* Other modern methods include Injections and Contraceptive jelly.

\section{Desire for Current Pregnancy}

The data shows that first births were rarely delayed and that a large number of men and women wanted the first pregnancy at the time the women became pregnant. However, among those who already had at least one living child a large proportion (41 percent of women and 37 percent of men) would have liked to have delayed the pregnancy or not wanted to have another child.

\section{Figure 3: Women and Men's Desire for Current Pregnancy}
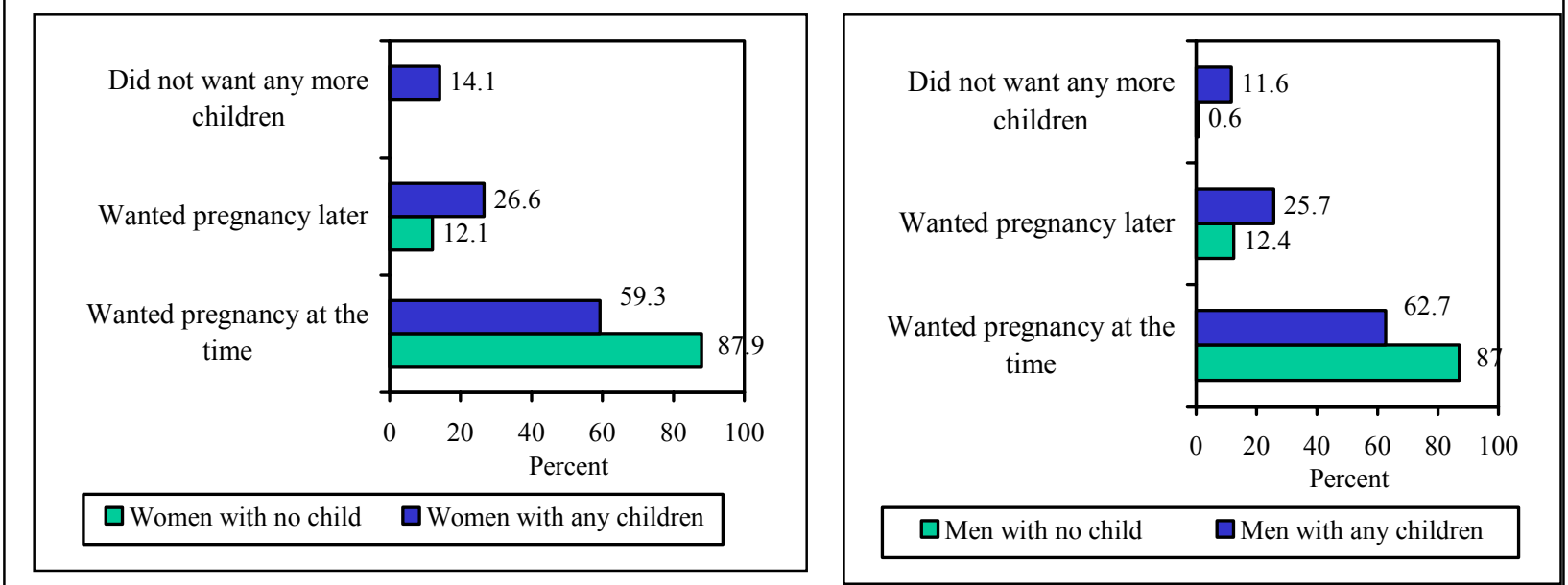


\section{Desire for More Children}

Responses showed that most couples followed the accepted norm of wanting at least two children, with at least one boy before completing their family. Among couples with no living child, most women and men reported that they would like to have another child, irrespective of the sex of index child. Those who desired another child, among couples who already had one child, did so mainly because of sex selectiveness. This was apparent since many respondents wanted a tubectomy after the present birth, and then later specifically mentioned that they would desire another child if the sex of the infant from the current pregnancy was not what they desired.

Table 5.4: Desire for Another Child after the Birth of Index Pregnancy among Men and Women

\begin{tabular}{|l|r|r|r|r|r|}
\hline \multirow{2}{*}{ Desire for another child } & \multicolumn{2}{|c|}{ Women } & \multicolumn{2}{|c|}{ Husband } & $\begin{array}{r}\text { Couple } \\
\text { Concordance } \\
(\mathrm{n}=488)\end{array}$ \\
\cline { 2 - 5 } & $\begin{array}{r}\text { With no } \\
\text { child } \\
(\mathrm{n}=190)\end{array}$ & $\begin{array}{r}\text { With at least } \\
\text { one child } \\
(\mathrm{n}=391)\end{array}$ & $\begin{array}{r}\text { With no } \\
\text { child } \\
(\mathrm{n}=161)\end{array}$ & $\begin{array}{r}\text { With at least } \\
\text { one child } \\
(\mathrm{n}=327)\end{array}$ & $\begin{array}{r} \\
\text { Want to have another child }\end{array}$ \\
& & & 8.9 & 29.3 \\
Yes, without sex preference & 89.5 & 11.0 & 89.4 & 3.4 & 0.2 \\
Yes, if this baby a boy & 0.5 & 2.0 & 1.2 & 7.0 & 1.4 \\
Yes, if this baby a girl & 1.6 & 11.0 & 0.6 & 76.5 & 40.0 \\
No/No more & 7.4 & 70.1 & 5.0 & 4.3 & 8.4 \\
Undecided/ Don't Know & 1.1 & 5.6 & 3.7 & \\
\hline
\end{tabular}

Family Planning Intentions among Women and Men who Wish to have Another Child

Fifty four percent of women and 57 percent of men did not intend to have another child. However more women than men intended using a family planning method to prevent pregnancy in the future. Of the 213 women who desired another child (irrespective of the gender of the current pregnancy) 41.3 percent intended adopting a spacing method. The most commonly mentioned method (28 percent) was oral contraceptive pills, followed by IUD (14 percent) and condoms (13 percent). Whereas among the 173 men who wanted another child (without mentioning a specific gender of child) only 36 percent planned to use a family planning method. The most commonly mentioned method was oral pills (33 percent) followed by condoms (32 percent), IUD ( 8 percent) and injections ( 6 percent). Thirty nine percent of both spouses stated the intention to use FP while 44 percent were discordant on using FP after the birth of index pregnancy. 
Table 5.5: Men and Women's Intentions to use a Family Planning Method after this Pregnancy by their Intention to have Another Child

\begin{tabular}{|l|r|r|r|r|}
\hline \multirow{2}{*}{$\begin{array}{l}\text { Family Planning Intention } \\
\text { ffter Birth of this child }\end{array}$} & \multicolumn{2}{|c|}{$\begin{array}{r}\text { Women wanting another } \\
\text { child }\end{array}$} & \multicolumn{2}{|c|}{ Men wanting another child } \\
\cline { 2 - 5 } & $\begin{array}{r}\text { Intend to } \\
\text { have } \\
(\mathrm{n}=268)\end{array}$ & $\begin{array}{r}\text { Do not intend to } \\
\text { have/Not sure } \\
(\mathrm{n}=313)\end{array}$ & $\begin{array}{r}\text { Intend to } \\
\text { have } \\
(\mathrm{n}=210)\end{array}$ & $\begin{array}{r}\text { Do not intend to } \\
\text { have/Not sure } \\
(\mathrm{n}=278)\end{array}$ \\
\hline & & & & \\
Yes & 44.0 & 80.5 & 37.6 & 70.1 \\
No & 50.7 & 16.0 & 57.1 & 26.6 \\
Don't Know/Undecided & 4.5 & 2.9 & 4.8 & 2.9 \\
\hline
\end{tabular}

\section{Preferred Source to Obtain their Chosen FP Method}

Most men and women surveyed mentioned the ESIC health care system as the preferred source of family planning method. Of the men who reported they intended using a method postpartum, 45 percent said they would obtain it from an ESIC hospital and 52 percent from the ESIC dispensary. Of the women who intended using a method, the corresponding percentages were 49 and 43, respectively.

\section{Source of Family Planning Information/Advice}

When asked whom they would speak to for advice on family planning, 85 percent of men reported an ESIC doctor, 6 percent stated that they would consult a private physician and 5 percent reported that they would refer to an ANM. Seventy two percent of the women reported that they would speak to a doctor and 6 percent said that they would consult an ANM.

\section{CHILD HEALTH}

The MiM intervention focused on women and men's reproductive health outcomes at six months postpartum. However, two determinants of infants' health were included in the outcomes, which would be measured in the postpartum survey at six months. These were age-appropriate immunization and exclusive breastfeeding. The couple counselling, had, in addition to LAM, strong recommendations for mothers to breastfeed exclusively for six months, whether they used it to prevent pregnancy or not.

In South Asian countries and India in particular, newborn breastfeeding is almost universal. Introduction of other liquids and semi-solids occur as early as when the infant 
is one month old. The WHO recommends exclusive breastfeeding for the first six months and adding other nutrients at six months of age but continued breastfeeding for two years.

In the baseline survey information was collected on immunization of living children and on intentions to breastfeed exclusively. The postpartum survey will document immunization when the new baby is six months old, and whether this is completed for age per India's norms and also the mother's breastfeeding practices at that time.

\section{Immunization of the Youngest Living Child}

Ninety percent of women who had one or more living children stated their youngest child was immunized. In the baseline survey, no attempt was made to determine the type of immunization and age according to national norms since the age of each child would be different at the time of measurement.

\section{Person Responsible for Bringing the Child for Immunization}

It was clear that men and women both understood that immunization was a joint responsibility. In nearly half the cases, parents, a relative or the father brought the child alone. In the rest, the woman alone had brought the youngest child for immunization.

Table 6.1: Person who took the Youngest Living Child to Clinic for Immunization

\begin{tabular}{|l|r|r|}
\hline Person who brought the child to the dispensary for & \multicolumn{2}{|c|}{$\begin{array}{c}\text { Women/men whose child } \\
\text { received immunization }\end{array}$} \\
\cline { 2 - 3 } & $\begin{array}{r}\text { Female } \\
(\mathrm{n}=581)\end{array}$ & $\begin{array}{r}\text { Male } \\
(\mathrm{n}=488)\end{array}$ \\
\hline Mother & 53.1 & 41.1 \\
Father & 10.5 & 17.5 \\
Both parents & 28.6 & 28.3 \\
Other family member/relatives & 7.8 & 11.5 \\
Other (Health workers came to house etc.) & 0.0 & 1.6 \\
\hline
\end{tabular}

\section{Intention to Breastfeed Exclusively}

Interestingly, more men ( 84 percent) than women ( 77 percent) stated they expected their child to be breastfed exclusively; 15 percent of the women stated they would not breastfeed exclusively and 7 percent reported that they were unsure. The hypothesis is that, with exposure to the intervention, a higher proportion of newborns will be exclusively breastfed for a longer time in the experimental group than in the control group of mothers. 


\section{PREGNANCY CARE}

\section{Reasons for Attending the Antenatal Clinic According to Women and their Husbands}

The Reproductive and Child Health Programme in India has given emphasis on early registration and the provision of at least three ANC visits for each pregnancy. However, the success of this mission largely depended on the perception of the expectant mother regarding the importance of receiving antenatal care. The reasons for these visits were asked of the women and men surveyed, and the responses showed that most people did know the purpose of antenatal care.

Table 7.1: Women and Men's Reported Reasons for the Importance of Antenatal Care

\begin{tabular}{|l|r|r|}
\hline \multirow{2}{*}{ Importance of maternity care } & \multicolumn{2}{|c|}{ Proportion of women/men } \\
\cline { 2 - 3 } & $\begin{array}{r}\text { Female } \\
(\mathrm{n}=581)\end{array}$ & $\begin{array}{r}\text { Male } \\
(\mathrm{n}=488)\end{array}$ \\
\hline To find out if pregnancy is normal & 55.9 & 62.7 \\
To find out if there are any problems & 47.8 & 59.8 \\
To get vaccinations & 31.8 & 19.7 \\
To get vitamins / iron & 24.6 & 18.9 \\
To get blood/urine tests & 16.7 & 10.5 \\
Don't Know & 8.3 & 4.7 \\
\hline
\end{tabular}

\section{Views on Harmful and Healthy Practices During Pregnancy}

Almost all the men and women stated that smoking, drinking alcohol and carrying heavy loads during pregnancy were harmful for a pregnant women and her fetus. This was reflected in practice too since less than 1 percent of women reported alcohol and tobacco use.

Table 7.2: Women and Men's Perception on Some Harmful and Beneficial Practices During Pregnancy

\begin{tabular}{|l|r|r|}
\hline Statements on Harmful/ Beneficial practices in Pregnancy & \multicolumn{2}{|c|}{ Proportion Agreed } \\
\cline { 2 - 3 } (Proportion of respondents reported YES) & $\begin{array}{r}\text { Female } \\
(\mathrm{n}=581)\end{array}$ & $\begin{array}{r}\text { Male } \\
(\mathrm{n}=488)\end{array}$ \\
\hline It is important for a pregnant woman to get extra food & 69.0 & 37.1 \\
It is important for a pregnant woman to get extra rest & 69.9 & 60.2 \\
It is harmful for the unborn baby if woman drinks alcohol & 93.8 & 95.9 \\
It is harmful for the unborn baby if woman smokes/chews & 94.5 & 96.3 \\
tobacco & & \\
It is harmful for a pregnant woman to carry heavy load & 98.1 & 95.7 \\
\hline
\end{tabular}


However, 53 percent men used tobacco and 33 percent reported alcohol use in the past three days. Men and women differed on the importance of extra food and rest during pregnancy with more women than men agreeing that extra food and rest were necessary.

\section{Knowledge of Danger Signs during Pregnancy and Postpartum}

Prompt recognition and immediate care seeking in the face of a danger sign were considered among the most important life-saving behaviors in pregnant and immediate postpartum women. Spontaneous multiple answers to knowledge of danger sign questions documented the number of men and women who mentioned at least one of the following: fever, bleeding, swelling of hands and face, high blood pressure, prolonged labor and premature rupture of membranes.

Table 7.3: Women and Men's Knowledge on Danger Signs During Pregnancy

\begin{tabular}{|l|r|r|}
\hline Knowledge of Danger Signs During Pregnancy & \multicolumn{2}{|c|}{$\begin{array}{c}\text { Proportion of } \\
\text { Men/Women }\end{array}$} \\
\cline { 2 - 3 } & $\begin{array}{r}\text { Female } \\
(\mathrm{n}=581)\end{array}$ & $\begin{array}{r}\text { Male } \\
(\mathrm{n}=488)\end{array}$ \\
\hline & & \\
Know one danger sign & 10.3 & 21.1 \\
Know two danger signs & 4.5 & 13.5 \\
Know three or more danger signs & 1.5 & 2.5 \\
Don't know any danger signs & 89.7 & 78.9 \\
\hline
\end{tabular}

Both men and women reported low knowledge levels of these conditions. The MiM intervention included repeated messages during couple counselling and inclusion in the women's pregnancy brochure of the danger signs as well as the care seeking each woman should adopt if they occurred.

\section{MALE INVOLVEMENT AND SPOUSAL COMMUNICATION}

\section{Men's role in Maternity and its Importance}

Men often accompanied their wives to the ESIC dispensary for ANC. However, they may assist in caring for a young child and can usually seen waiting in queues at registration or pharmacy counter or outside the clinic.

The objectives of the MiM project have been based on the premise that inviting and involving men in their wives' maternity care will positively affect family planning, STI- 
HIV/AIDS, child health and pregnancy outcomes. The intervention seeks to address men as individuals and partners in antenatal and postpartum care through couple counselling and individual counselling on STI preventive practices after his wife has given her informed consent for his participation. In order for men to be more supportive of their wives, especially during maternity, basic knowledge, open communication channels, and sensitisation to their wives' needs is essential.

\section{Male Involvement and Spousal Communication Data}

Data is presented on selected indicators of male involvement and spousal communication. Ninety seven percent of women and 98 percent of men said that the husband was providing financial support to the wife. Ninety five percent of women said they received encouragement from their husbands to attend ANC. On asking how husbands encouraged the wives, many said they encouraged their wife to: "Go for regular check-ups during pregnancy so that we know that everything (health of mother and unborn baby) is alright, and "Do less work and pay more attention to medical check-ups and food." and "Visit the doctor and take medication on time."

\section{Presence of Husbands at the Dispensaries}

The Men in Maternity intervention envisages men accompanying women to the clinic and also encourages husbands to participate in counseling sessions and to accompany their wives to hospital during emergencies and for delivery. Men are again encouraged to come with their wives and infant to the clinic for a six-week postpartum checkup and counseling.

Husbands of 63 percent women were present during the visit to the dispensary on the day the women were interviewed. Women reported comfort, support and assistance in dealing with health providers as the main benefit when husbands accompanied them to clinic. Almost all the women said they would like to involve their husbands in different stages of maternity care. However one-third of women did not want their husbands' presence during examination and labor/delivery. There was hardly any difference in women's perceptions and their husbands' regarding the latter's involvement in maternity care. 
Among those not wanting husbands involved, the main reasons included: women were unwilling to be accompanied by their husbands ( 32 percent), felt it was a women's business/not a place for men (22 percent), thought their husbands would feel embarrassed (16 percent) or thought that their husbands would not be allowed to remain with them (14 percent).

Based on the survey almost all the men (98 percent) said that their wives would like to be accompanied by their husbands for maternity care. Currently 60 percent had been accompanying their wives to clinics. About 95 percent of men said they wanted to be present during different stages of maternity care such as during consultations/group discussions, family planning consultations, paying for treatment and medicines. A higher percentage of husbands than wives said that they wanted to be present during labor/delivery and examinations (71 percent and 78 percent respectively) compared to the women (64 percent).

\section{Husband's Help during the Maternity Process}

When asked about the ways in which husbands could help during pregnancy and after childbirth, 70 percent of women said that husbands could help in household chores, 30 percent and 23 percent of women respectively said that their husbands could help in carrying heavy loads and looking after the children. When asked the same to men, 78 percent of the men said they could help in cooking and washing, 40 percent said they could carry heavy loads and 11 percent reported they could help in taking care of the children.

\section{Husband's Assistance in an Emergency}

Fifty two percent of women mentioned that they had discussed what to do if there was an emergency and she needed to go to hospital. All the women reported that her husband would assist her to get to the hospital in case of any emergency or if any danger signs of pregnancy arose.

\section{Spousal Communication and Consultation}

More than three-fourths of the women said they had discussed maternity care and plan for birth with their husbands. About half of the women said they had discussed family 
planning. However, only about 8 percent women mentioned having discussed STIs and HIV/AIDS with their husbands.

The survey showed, in general, that couples took joint decisions on family health issues. But wherever individual decision-making was required, husbands were the key decision makers. 14 percent of women revealed that they decided and 35 percent of women said that their husbands decided whether to go to clinic if they were feeling unwell.

\section{Spousal Abuse, Perceptions and Prevalence}

Domestic violence hampers couple communication and can be a barrier to joint decision making and negotiation on the use of family planning methods, STI preventive measures and risk reduction.

Table 8.1: Women and Men's Perception on Justification for Physical / Emotional Violence

\begin{tabular}{|c|c|c|c|c|c|c|}
\hline \multirow[t]{2}{*}{ Circumstances } & \multicolumn{3}{|c|}{$\begin{array}{c}\text { Proportion of Women } \\
\text { who said it was } \\
\text { justifiable }\end{array}$} & \multicolumn{3}{|c|}{$\begin{array}{l}\text { Proportion of Men who } \\
\text { said it was justifiable }\end{array}$} \\
\hline & Yes & No & $\begin{array}{r}\text { DK/ } \\
\text { CS }\end{array}$ & Yes & No & $\begin{array}{r}\text { DK/ } \\
\text { CS }\end{array}$ \\
\hline If she neglects children & 7.4 & 92.4 & 0.2 & 12.7 & 77.7 & 9.6 \\
\hline If she argues with him & 13.3 & 86.4 & 0.4 & 12.1 & 82.4 & 5.5 \\
\hline If she refuses to have sex with him & 1.7 & 98.1 & 0.2 & 2.3 & 94.9 & 2.9 \\
\hline $\begin{array}{l}\text { If she wants to talk about using } \\
\text { family planning methods }\end{array}$ & 1.0 & 98.5 & 0.5 & 1.6 & 96.1 & 2.0 \\
\hline If she asks him to use condoms & 1.0 & 98.5 & 0.5 & 2.0 & 96.7 & 1.2 \\
\hline If she neglects food preparation & 8.8 & 90.9 & 0.3 & 9.4 & 84.0 & 6.6 \\
\hline If she is seen with another man & 35.1 & 64.4 & 0.5 & 24.8 & 51.8 & 23.4 \\
\hline All respondents (Intervention) & \multicolumn{3}{|c|}{581} & \multicolumn{3}{|c|}{488} \\
\hline
\end{tabular}

Both men and women were first asked if her husband had ever abused her and/or in the past year during this pregnancy. Results on reports of actual violence revealed that 20 percent of women reported having faced some form of violence in their marriage. An equal proportion of men reported mistreating their wives. The commonest form was verbal abuse followed by forced sexual intercourse, slapping and threats to turn the woman out of the house. Five percent mentioned forced sex even during the current pregnancy. They were then asked if any of abuse was justifiable under a set of 
circumstances. Men justified the violence more than women. Some of the reasons for abuse women considered justifiable included being seen with another man; arguing with their husband; negligence towards the children and the kitchen.

\section{CLINIC SERVICES}

\section{Impact of the Intervention at the Clinics}

The MiM intervention caused very notable changes in the dispensaries and quality of antenatal care. These changes included making men feel welcome participants in their wives' pregnancy care and helping doctors and ANMs counsel couples and individuals on STI protective behaviours including condom use demonstration on a penis model.

This section provides selected data on women's and men's perceptions, before the intervention was put in place, on whether men were welcome at the ANC clinic and reasons why some men did not feel welcome. In addition it is hoped that men's involvement and ANM's important role in ANC will increase men's and women's willingness to consult doctors and ANMs on family planning and STIs.

\section{Whether Women and Men Felt Welcome at the Clinics}

Forty four percent of women said they felt welcome at the ANC clinic and 55 percent said they didn't know. Ninety three percent of women said their husbands felt welcome at the clinic and rest said they did not know. Eighty five percent of men reported they felt welcome at the clinic but 12 percent said they were not. The main reasons cited by men for not feeling welcome were not enough time from doctors, long waiting time for registration, non-availability of desired medicines, behaviour of staff, among others.

\section{Seeking Advice on Family Planning}

Eighty percent of women said that they would seek advice on family planning from an ESIC doctor or ANM/nurse. Only 2 percent of women reported that they would seek advice from other health sources. More than three-fourths of the women said that they would go to an ESIC hospital or dispensary for seeking information on STIs and HIV/AIDS. Only about 5 percent of women said that they would go to other sources like 
a pharmacy/shop, private doctor, among others, to access the information on STIs and HIV/AIDS.

Prior to the MiM implementation, ANMs did not play an active part in counselling women in contraception during antenatal clinics. The doctors conducted this selectively for higher parity women. In the MiM experimental clinics, as part of the intervention, ANMs primarily provided FP couple counselling both in ANC and PP clinics. Both ANMs and doctors of the experimental clinics were trained and encouraged to explain all family planning methods available and to allow couples to make informed choices of their preferred methods.

Table 9.1: Women and Men's Report on Any Informational Materials Received at the Antenatal Clinic

\begin{tabular}{|l|r|r|}
\hline & $\begin{array}{r}\text { Female } \\
(\mathbf{n = 5 8 1})\end{array}$ & $\begin{array}{r}\text { Male } \\
(\mathbf{n = 4 8 8})\end{array}$ \\
\hline Received informational materials at ANC & 0.2 & 15.5 \\
Self & 0.2 & - \\
\hline Contents of materials & & \\
$\quad$ Infant health & 0.2 & 4.7 \\
Maternal Health & 0.0 & 4.5 \\
STDs & 0.0 & 0.4 \\
FP & 0.2 & 4.1 \\
\hline Discussed contents with Spouse & & 10.2 \\
\hline Source of Additional Information on STIs and & 29.4 & \\
HIV/AIDS & 39.8 & 31.4 \\
ESIC Hospital & 0.9 & 56.8 \\
ESIC Dispensary & & 5.7 \\
Private Provider & & \\
\hline
\end{tabular}

In the survey, questions were also asked about whether they had received any informational materials while visiting the clinic for maternity care and what the content of the material was.

\section{SUMMARY AND DISCUSSION}

The MiM intervention is facilitating the inclusion of husbands in their wives' maternity care with couple and individual (or same sex group) counseling during pregnancy and at six weeks postpartum. Counseling is focusing on healthy pregnancy behaviors, care 
seeking in the face of danger signs, postpartum family planning including LAM and improving knowledge on STIs and HIV, their prevention and care seeking if symptoms of male urethritis or male and female genital ulcers are present.

In order to accomplish this, Antenatal and Postpartum services were changed to include more couple and individual counseling on aspects outlined above, and established universal syphilis screening at each participating clinic. Besides this BCC materials were developed for providers and clinic clients. These changes in maternity services were accomplished by utilizing existing dispensary staff with ANMs providing the principal couple counseling sessions and also having women and men separately counseled, in a culturally more acceptable manner, by male and female doctors.

The data presented in this report derives from interviews conducted before the pregnant woman was seen for ANC at six ESIC dispensaries in cases where she was between 10 and 26 weeks pregnant. Interviews were conducted after their consent and in all cases of men's interviews, only with his wife's permission. Both men and women were interviewed in the experimental clinics and only women were interviewed in the control clinics. From this data the following conclusions have been drawn:

- Most women who were informed of this project agreed to participate and, in the case of the experimental clinics, to involve their husband both in the research and the new service/counseling model. There were very few refusals to participate in the research and they were mostly due to length of time that the interview would take.

- With few minor differences, control and experimental women were quite similar in their socio-demographic characteristics.

- In general terms, participating women were 4.5 years younger and far less educated than their husbands. Only 7 percent of the experimental women were under 20 years of age and 36 percent were illiterate, with an additional 4 percent having attended five to seven years of schooling. Most were married over two years. Although men, usually the ESIC beneficiary, were universally working for income, only 8 percent of the women were doing so.

- About four-fifth of the households had either a radio or television, leading to the conclusion that mass media had a wide outreach among the majority of the ESIC 
population. This could also account for the high level of knowledge found on some of India's priority health concerns (family planning, child spacing, HIV/AIDS).

\section{Pregnancy history}

- This cohort of women was generally of low parity, with only 8 percent of the intervention women having three or more children. The mean number of living children for the intervention group women was 1.1. The corresponding figure for currently married women aged 15-49 in Delhi is 2.5 children (NFHS II, 1999). Seventy seven percent of the women had had a previous pregnancy but 67 percent of them had a living child. Twenty six percent of women reported having had a miscarriage and 7 percent an MTP (elective abortion).

\section{Unmet family planning need}

- Data revealed that an MTP/ elective abortion varied with the number of living children of women. This ranged from 1.8 percent among women with no child to 10.2 percent of women with 3 or more children, prior to this pregnancy. This is an indication of high FP unmet need in the ESIC population, especially among the women with higher number of living children, and of MTPs being used as a FP measure.

- Other strong indicators of unmet need were short spacing in 25 percent of the women who had children although the stated preference by 42 percent of the women was that the current pregnancy should have taken place later or not at all. In 25 percent of women with one or more living children, the age of the youngest child was under 21 months showing no FP use for spacing births.

\section{Future Desired Fertility and FP Intentions}

- Ninety percent of women expecting their first child and 11 percent of those who had one or more children stated they wanted to have another child; the great majority wanted to wait at least two years. The stated preferred waiting period was in probability a reflection of media messages than of women's real attitudes. Seven percent of women expecting their first child and 70 percent of those who had one or more living children stated the clear preference of having no more children after the 
birth of index pregnancy. The remainder of women were undecided or otherwise whose decision depended on the sex of the expected child.

- Of the women who preferred to wait at least two years, 44 percent stated they intended to use a method. Of those women who did not want more children, only 68 percent stated they intended to use a pregnancy preventing method. And, 10 percent of the women who stated they wanted another child said they intended to use tubectomy after the birth only if the sex of the expected child was what they desired.

- When asked where they would obtain FP methods and advice, the large majority of respondents, both men and women stated they would use ESIC's services. However, very few women and no men mentioned the ANM as the health care provider from whom they would seek advice.

\section{Gender Roles and Decision Making}

- Almost all women and men stated that they would like to attend ANC services jointly. Two-third of the women wished to have the husbands present during the physical exam and labor and birthing, as did three-fourth of the men. This is a surprisingly high proportion given traditionally held perceptions on gender roles and the current situation where men accompanied their wives but did not participate in antenatal and postpartum services.

- Crowded living arrangements, often in extended families, and long working days were not conducive to intimate communication between spouses. However, over half of the women reported having discussed family planning with her husband and higher proportions discussed maternity care and plans for the birth of the expected child. Breastfeeding and STIs and HIV/AIDS were discussed much less frequently (28 percent and 12 percent). Regarding decision-making in reproductive matters (when to have children, whether to use FP and which method to use), most decisions were taken as a couple, but when it was only one spouse who made the decision, it was almost always the husband.

- Twenty six percent of couple showed concordance in intention to have another child after the birth of index pregnancy. Another 34 percent showed concordance in not wanting to have any more children. Thirty nine percent of both spouses stated the intention to use FP while 44 percent were discordant on using FP after the birth of index baby. 
- One fifth of the women reported that they had ever experienced any violence from their spouse. Significantly 10 percent of women said they were physically forced by their spouse into having sex against their wishes.

\section{Reproductive health knowledge}

- Reproductive health knowledge, including fertility cycle, danger signs in pregnancy, importance of exclusive breastfeeding, LAM, and HIV/AIDS was uniformly low in the population represented by the interviewed men and women. However, in all cases, men appeared to know more than their spouses, even about women's reproductive health. This difference could be attributed to husbands' higher educational level and exposure to media/IEC by virtue of their working outside the home.

- Although most men had heard of HIV/AIDS, most women did not, and both genders possessed low specific knowledge of this disease. STI knowledge was even lower, particularly men's knowledge of urethral discharge symptoms as indicative of an STI. Women had extremely limited knowledge of any STIs and their symptoms.

- Women and to a lesser extent men, had very low knowledge of danger signs in pregnancy, birth and immediate postpartum. Of women who had at least one child before this pregnancy and therefore was exposed to the maternity process earlier, only 6 percent knew of one danger sign, 3 percent knew of two signs and 89 percent knew none. MiM, both in the counseling of pregnant women and their husbands and IEC materials, had stressed these aspects of pregnancy.

\section{STI symptoms}

- In the ESIC served population of married, low parity couples there appeared to be a very low reporting of risky behaviors both in men and women. However, a not negligible 9 percent of men reported having had burning during urination or discharge in the last six months preceding the survey. Only two-third of men that reported the above symptoms sought any treatment. Of those who sought treatment, only 14 percent said their spouse received any treatment, however 65 percent stopped having sex during treatment and 10 percent reported using condoms. 
- The MiM intervention educated both providers and clients on updated aspects of contraception and the substantial benefits of exclusive breastfeeding and LAM. Individual and couple counseling was added for the first time with maternity care services to address husband's care and antenatal support, knowledge, FP use and infection prevention. Universal syphilis screening of AN clients and postnatal care for mother and child were also the added components of the MiM intervention. Condom use, and dual protection education was being provided for the first time to both men and women.

Overall, the low levels of knowledge of danger signs during pregnancy, low levels of knowledge of STIs, high unmet need for FP, high desire of spousal involvement in maternity care among low parity younger age couple points to the need for ESIC providers and managers to work towards addressing these issues and which in turn, may enhance FP use and promote STIs preventive practices. 


\section{REFERENCES}

Varkey, Leila Caleb. Involving Men in their Wives' Antenatal and Postpartum Care in India. Research Update, March 2001. New Delhi, India: Population Council/FRONTIERS.

Das, Anjana, Leila Caleb Varkey, Anurag Mishra, Emma Ottolenghi, and Dale Huntington. Men in Maternity Study. Research Update, April 2002. New Delhi, India: Population Council/FRONTIERS.

Mishra, Anurag, Leila Caleb Varkey, Emma Ottolenghi, Anjana Das, Dale Huntington, and Susan Adamchak. Men in Maternity: A Summary of the Findings from PreIntervention Interviews with Women and their Husbands Attending Antenatal clinics at ESIC Facilities in Delhi. FRONTIERS Research Update, July 2002. India. 